\title{
ERRATUM
}

\section{Cacao liquor procyanidin extract improves glucose tolerance by enhancing GLUT4 translocation and glucose uptake in skeleta muscle - ERRATUM}

\author{
Yoko Yamashita, Masaaki Okabe, Midori Natsume and Hitoshi Ashida
}

Journal of Nutritional Science (2012), vol. 1, e6, page 1 of 1

doi:10.1017/jns.2012.9

The received date of the article by Yamashita et al. (2012), presented in Journal of Nutritional Science, was given incorrectly. The correct received date is 23 October 2011. The editorial office apologise for any confusion caused.

\section{Reference}

1. Yamashita Y, Okabe M, Natsume M et al. (2012) Cacao liquor procyanidin extract improves glucose tolerance by enhancing GLUT4 translocation and glucose uptake in skeletal muscle. J Nutr Sci 1, 1-9.

(C) The Author(s) 2012. The online version of this article is published within an Open Access environment subject to the conditions of the Creative Commons Attribution-NonCommercial-ShareAlike licence <http://creativecommons.org/licenses/by-nc-sa/2.5/>. The written permission of 